\title{
The Impact of Applying IFRS (9) on Investors' Decisions: An Applied Study on the Companies Listed on Amman Stock Exchange (ASE)
}

\author{
KARAM HABAWAL \\ Applied Science Private University \\ SALEH K. ALOKDEH \\ Professor Applied Science Private University \\ Email: $\underline{\text { s_okdeh@asu.edu.jo }}$
}

\begin{abstract}
This research aims to examine the impact of applying IFRS (9) in the preparation of financial reports by taking into consideration: the scope, recognition, classification, and the measurement on the decisions of investors from the view point of brokerage managers, investment managers, and financial analysts in companies listed on the Amman Stock Exchange investment companies. The descriptive analysis methodology is used and the questionnaire is also used as a tool of collecting data for this research. Questionnaires have been distributed on a sample consisting of 33 investment firms listed on Amman Stock Exchange (ASE). The research finds that there is an impact of applying IFRS 9 by the scope, recognition, classification, and measurement on investors' decisions.
\end{abstract}

Keywords: Investment Decision, International Financial Reporting Standard (9), Scope, Recognition, Classification and Measurement.

\section{Introduction}

The historical cost has been the concept used for measurement. Until late seventies, an alternative to this concept has begun to be considered. Such an alternative should have the necessary characteristics to meet the needs of financial data users including shareholders, investors, and others, and it should also provide better assessment to the financial instruments, investments, and obligations. The historical cost is characterized by the stability of the monetary unit under different economic conditions; this would make it an objective measure which does not provide confidence in financial data, in addition to its ability to provide users with a better quality of information; through which the decision maker will be able to depend on the audited financial statements (ascajordan.org). Hence, the Financial Accounting Standards Board (FASB) in the US, together with and the International Accounting Standard Board (IASB) have issued a group of standards as a contribution to providing proper information for their users. On 1993, the FASB has issued standard 115 and the IASB has issued standard 32: Financial Instruments (presentation and disclosure). Subsequently, standard 29 related to (Financial instruments: recognition and measurement), along with its subsequent amendments has been issued on 1999. Following this, the IFRS 7: (Financial instruments: disclosures) has been issued on 2005. In addition, the disclosure requirements have been moved from the IAS 32 which was reclassified as (Financial instruments: presentation). All efforts made in this direction have aimed at providing new concepts for qualitative accounting information that serve the purposes of users in all their orientations. Worldwide, many users of the accounting information, as well as many relevant parties have faced a difficulty in the understanding and application of the IAS 39: (Financial 
instruments: recognition and measurement). Therefore, the IASB has been required to issue a new financial reporting standard on the financial instruments that is easy and simple. The IASB has thus accelerated the replacement of IAS 39 by dividing the new project into three phases. The main focus of the first phase is on the "classification and measurement of financial assets"; whereas other phases have addressed the "Impairment of financial instruments" and" Hedge accounting". The purpose for this is to completely replace the IAS 39 by the end of 2010 through the phased issuance of IFRS 9 "Financial Instruments". On September 2009, the Board has published a draft presentation entitled "Financial instruments: classification and measurement". Moreover, the IFRS 9 "Financial instruments" has been issued on November 2009 and then reissued on 2010. The date of application has been set on 1 January 2013; however, on 2012, due to the non-fulfillment of the financial instruments requirements, it has been deferred to become effective as of 1 January 2015, with an early application being permitted before that date. Finally, during the Board meeting on February 2014, the mandatory date for the application of the Standard has been decided to be set on the 1st January 2018.

This standard has caused many improvements to the IAS 39. One of the most important of these improvements is the amendments related to the classification and measurement of financial assets. The impact of these amendments has been shown on the information presented in the financial statements. Such a matter has led to questioning the impact of these amendments on investors' decisions.

\section{Study Problem}

Due to the sensitivity and importance of this standard and the differences it has brought to increase confidence in the financial information, the study problem comes to show the extent to which investors are influenced by the changes in the financial statements of companies listed on the ASE that applied the IFRS 9. Therefore, the study problem resolves around the following main question:-

What is the impact of applying the IFRS 9 in companies listed on ASE on investors' decisions?

The following sub- qeustions are derived from the above question:-

a) What is the impact of the compliance of companies listed on ASE with the application the IFRS 9 on investors' decisions?

b) What is the impact of the compliance of the companies listed on ASE with the recognition of financial transactions and operations in accordance with the requirements of IFRS 9 on investors' decisions?

c) What is the impact of the compliance of the companies listed on ASE with the classification of financial assets and liabilities in accordance with the requirements of IFRS 9 on investors' decisions?

d) What is the impact of the compliance of the companies listed on ASE with the measurement of financial assets and liabilities in accordance with the requirements of IFRS 9 on investors' decisions?

\section{Importance of the Study}

The importance of the study stems from the following:-

The IFRS 9 is an important turning point as a result of its amendments made on the financial instruments in several aspects, including: classification and measurement. This standard has classified all financial assets into two categories; the first of which is the financial asset measured in amortized cost and the second phase is the financial asset measured in fair value either through (profit or loss) or by the other comprehensive income. Financial instruments are classified in accordance with this Standard based on the establishment business model for managing financial assets as well as the contractual cash flow characteristics of the financial asset (Abu Nassar, Hmeidat 2014). It is important to mention that many categories have been canceled from the IFRS 9; they include: Available-for-sale financial assets, held-tomaturity financial assets, as well as loans and receivables). On the impairment side, this Standard has 
introduced an important amendment where it replaced the "incurred- loss " model in IAS 39 with the "expected credit loss" model being applied to financial assets which are not measured in fair value by the profit or loss (Takrouri, 2015). These amendments and others have aimed to reinforce the relevancy feature of the presented accounting information as these changes have affected the volume of calculating profits, as well as on how allocations are calculated, whether they are directly related to the income account or capital account, depending on how to deal with low-value assets, especially investments.

Moreover, the Securities Commission has obliged companies to the early application of the IFRS 9 as of the financial year 1/1/2011 under article no. (3) of the Instructions on the Re- evaluation of Fair Value and Disposal of Re-evaluation Surplus for the year 2011 issued on 18/1/2011. Hence, the importance of this study stems from the impact of applying this standard on investors' decisions in the ASE.

This study is considered important for financial statements users as it sheds light on the IFRS 9. The most significant changes introduced by this Standard to the financial statements when applied as being an alternative to IAS 39 (Financial Instruments) are the Recognition and Measurement.

\section{Study Objectives}

This study aims at shedding light on the impact of applying the IFRS 9 on investors' decisions in ASE. The most important study objectives can be summarized as follows:-

1. Identifying the impact of the compliance of companies listed on ASE with the application the IFRS 9 on investors' decisions.

2. Identifying the impact of the compliance of companies listed on ASE with the recognition of financial transactions and operations in accordance with the IFRS 9 on investors' decisions.

3. Identifying the impact of the compliance of the companies listed on ASE with the classification of financial assets and liabilities in accordance with the requirements of IFRS 9 on investors' decisions.

4. Identifying the impact of the compliance of companies listed on ASE with the measurement of financial assets and liabilities in accordance with the requirements of IFRS 9 on investors' decisions.

\section{Theoretical Framework}

\section{IFRS 9}

The project for replacing the IAS 39 with IFRS 9 has come in response to the need for improving and simplifying the preparation of financial reports for financial instruments, as well as a response to the needs of financial statements users and other interested parties who have been always calling for the development of a new financial reporting standard for financial instruments and that is easy and which adopts a unified basis for measurement and recognition. The global financial crisis has the greatest impact on emphasizing the urgent need for such a transition. As a result of the proposed guidelines to improve the preparation of financial reporting, in addition to the outputs of the meetings held between the FASB and the Financial Crisis Advisory Group (FCAG) on June 2009, as well as the decisions of G20 summit, this project has been divided into three main phases; First is the classification and measurement of financial instruments; second is the impairment approach; and third is the Hedge accounting (Arnouq, 2012).

The IFRS aims at setting foundations and principles related to the financial reporting on financial assets. Such principles would in turn provide relevant and useful information to financial data users in order to assess the amounts, timing, and uncertainty over the future cash flows of an establishment (International Financial Reporting Standards (IFRSs) Foundation, 2015). On June 2014, the full version of IFRS 9 has been issued; thus, completing the final phase of the standard. This version will replace previous versions of the standard issued on July 2014 and will be effective as of 1 January 2018. However, the establishments 
which have adopted or will adopt the previous version before January 2015 may continue to apply this version until the actual mandatory effective date on 1 January 2018 (www.kpmg.com).

Financial instruments are highly important in the statement of financial position as they are considered to be the main items in the statement of financial positions of many establishments. Financial instruments consist of financial assets, financial liabilities, and equity instruments. The increasing demand for investment in shares, bonds and derivatives by different business establishments has clearly shown the impact of these investments on the financial statements of these institutions.

Furthermore, many international standards addressing one aspect or more of the financial instruments have been issued as follows: IAS 32: Financial instruments: (Presentation), IAS 7: Financial instruments (Disclosure), IAS 9: Financial instruments: (replacement of the IFRS 39 (Recognition and measurement)).

\section{Investment}

The main objective of the investment decision for individuals or institutional investors is to maximize the return on investment within the acceptable level of risk. Therefore, the investor's success to reach his/ her goal depends on the extent to which he/ she can manage their investment. Investment derives its original concept from the investment science and it is related to a range of other concepts including income, consumption, savings, and borrowing. It is thereby difficult to understand investment unless its relationship with other economic concepts is analyzed.

Investors are the most prominent users of corporate financial statements. The conceptual framework for the preparation and presentation of financial statements indicates that investors are the party which provides the capital and they are the most risk- tolerant. Therefore, providing investors with the information they need to make investment decisions will meet most other users' needs for financial statements.

There are many definitions for investment as indicated by (Qassas, 2002):-

- "The process through which - based on an administrative decision - certain allocations whether fixed assets or cash are set in order to achieve long term objectives for the benefit of a particular project".

- "The dealing with money for gaining profit, only by sacrificing something now against something subsequently acquired as a current value against a future value, or as an instantaneous consumption versus future consumption".

- "It is that part of the income that is used in the production process for the formation of the capital and the increase of the production capacity. The capital formation consists of the fixed capital reserve and the change in stock".

(Matar, 2015) has defined investment as "the abandonment of money held by individuals at a particular moment and for a certain period of time in order to obtain future financial flows to compensate for the current value of the invested funds as well as the expected decrease in their purchasing value due to the inflation factor, taking into consideration that a reasonable return is provided against the risk component represented by the probability that such flows may not be realized".

There are three situations facing the investor and which require him/ her to take a decision, which will depend on the nature of the relationship between the price of the investment instrument on the one hand and the value from his point of view on the other hand. Within this framework, three types of investor decisions are derived as follows (Matar, 2015):

1. The purchase decision: The investor makes the purchasing decision when he/ she feels that the investment instrument value, represented by the current value of the expected cash flows and calculated in the framework of the return and risk, exceeds its market price, meaning that when the market price, symbolized by the letter $(\mathrm{M})$, is less than the investment instrument value, symbolized by the letter $(\mathrm{V})$, according to the investor's point of view, i.e. when $(\mathrm{V}>\mathrm{M})$. Therefore, this generates an 
incentive to buy that instrument with the aim of achieving capital gains through an expected increase in its future market price.

2. The non- trading decision: Based on the previous case resulting from the purchasing pressures, the market should respond to these pressures, so the instrument price continues to rise to a point, where the market price (M) equals the value $(\mathrm{V})$ from the investor's perspective. In such a case, the market will be in a state of equilibrium requiring all those who have motivations for purchasing or selling to stop the purchase and the sale. Therefore, the investment decision in this case will be non- trading where $(\mathrm{M}=\mathrm{V})$ because the investor in this point will have no hopes to achieve future capital gains as well as he/ she will avoid, even temporarily, the risks of falling price in the near future unless the prevailing conditions change and therefore, he/ she will decide to maintain the investment instrument.

3. The sale decision: After the equilibrium phase when the instrument price equals its value, the dynamism of the market will introduce additional desires in the market to purchase that instrument from a new investor according to his/ her own decision model. This means that the investor believes that $(\mathrm{M})$ in that moment is still less than $(\mathrm{V})$; therefore, he/ she will be required to provide a new price for that instrument greater than $(\mathrm{V})$. In this case, the price will be more than the value thus, casing a motivation for the sale. The investor's decision will be then the sale.

\section{Literature Review}

There are many studies that have tackled different aspects of the study subject, and we try here to summarize the most important previous studies which are considered the closet to the subject of this study. As for the Arabic studies, we begin with the study of (Qassas, 2002) that aims at identifying the investor's perspective of ASE in regards to the impact of the information and data of the annual financial reporting provided to the Jordanian commercial banks on his/ her investment decision. As well, this study has also investigated the extent to which the annual financial reporting provided to Jordanian commercial banks are important and relevant to the investment decisions in the ASE, examined the relationship between the item importance and its degree of disclosure in the annual financial reporting of Jordanian commercial banks, and revealed any difference in the assessment of the relative importance of items relating to financial instruments indicated in the requirements of IAS 39. One of the most important findings of this study are that most investment decisions are taken based on the information analysis according to specified models, and that the annual financial reporting of the Jordanian commercial banks are the most important information sources, on which the investor depends in ASE. Moreover, the study has considered all items pertaining to the disclosure of financial instruments and which are indicated amongst the IAS 39 are very important according to the study sample's viewpoint. Therefore, this would reinforce the importance of applying this standard to increase the disclosure in the annual financial reporting of Jordanian commercial banks.

Another study by (Dakhl Allah, 2015) aims to investigate whether the application of IAS 39 has caused positive changes in the financial statements of Jordanian commercial banks as well as to identify the extent to which these changes have an impact on the shares returns in Jordanian commercial banks. One of most important results of this study is that there are problems relating to the identification of the fair value and this is supported by many opinions and personal judgments. Although there are reasons for adopting the fair value as a solution to the management's problem of retaining or abandoning a financial instrument, this leads to the assumption that the reliance on the fair value alone is not appropriate and affects the comparability principle of the financial statements. Furthermore, the study has revealed that there is a positive impact of the application of the IAS 39 on the budget items, in addition to its impact on stock returns.

Moreover, the study of (Najjar, 2013) aims to show the impact of applying the fair value accounting on the reliability and relevancy of the accounting information presented in the financial statements of the Palestinian public corporations, in addition to identifying the problems and obstacles facing the application of fair value accounting of the Palestinian public corporations. The study has reached many findings; one of 
which is that the application of fair value accounting by Palestinian public corporations increases the degree of reliability and relevancy of the information presented in their financial statements and that the application of fair value accounting by corporations is facing many obstacles, such as the unavailability of active and relevant markets for measuring the fair value of many assets in Palestine.

The study of (Al Hyesat, 2013) aims at identifying the extent to which investors rely on the information indicted in the financial statements of the service sector shareholding companies listed on ASE in taking appropriate investment decisions as well as the extent to which these information are relevant to taking appropriate investment decisions, in addition to identifying the relationship between the relative importance of the items presented in the financial statements and their degree of disclosure to the service sector shareholding companies listed on ASE, and finally revealing whether there are statistically significant differences for the impact of disclosure in financial statements on investors' decisions in these companies. The study finds that investors rely on the information indicted in the financial statements of the service sector shareholding companies listed on ASE in taking appropriate investment decisions, that the information presented in the financial statements of service sector shareholding companies listed on ASE are relevant to take appropriate investment decisions, and that there is a relationship between the item importance and its degree of disclosure in the annual financial reporting of the service sector shareholding companies listed on ASE.

As well, the study of (Takrouri, 2015) aims to examine the difficulties facing Jordanian banks in the compliance with the early application of IFRS 9. The study finds that Jordanian banks do not face difficulties in the early application of IFRS 9, "Financial Instruments" whether in terms of the compliance with the application of the standard scope, the compliance with the recognition of financial transactions and operations in accordance with the requirements of the IFRS 9, the compliance with the classification of financial assets and liabilities in accordance with the requirements of the IFRS 9, or the compliance with the measurement of financial assets and liabilities in accordance with the requirements of the IFRS 9.

Next comes the study of (Al Khatib, 2015) which aims at shedding light on the impact of applying the IRFS 9 in terms of measurement of the accounting information quality represented by each of (relevancy, faithful representation, comparability, verifiability, understandability, and timeliness) in Jordanian commercial banks. The study results indicate that there is an impact of applying the IRFS 9 in terms of measurement on the improvement of the accounting information quality.

In regards with the foreign studies, the study of (Alkhadash \& Abdullatif, 2009) aims to analyze the impact of applying the fair value accounting of financial instruments on the company's financial performance and its earnings per share. The study covers the Jordanian commercial and investment banks during the period from 2002 to 2006. The researchers have compared between the accounting results published by the fair value and those calculated using the cost principle for the same years. As well, the researchers have analyzed the change resulting from the fair value accounting in the financial results as well as the extent to which financial statements information are relevant to the users of these statements. The study finds that financial performance of banks has been significantly affected by the evaluation of financial instruments at the fair value as there were highly positive values for the earnings per share when applying the fair value on the financial instruments evaluation compared to the earnings obtained from the de- recognition of financial instruments holding. The study concludes to question that extent to which the application of the IRFSs to the fair value accounting is valid in the same way globally.

Another study by (Alhayek \& Elhaija, 2011) aims at evaluating the ability of accountants in Jordanian banks to reflect the requirements of the IRFS 9 on financial activities. The researchers have focused within this standard on measuring financial assets and liabilities, the impairment concept, hedge accounting, insurance, and financial leasing, in addition to showing how accountants have dealt with these topics. The study concludes that accountants at Jordanian banks have the adequate knowledge of the IRFS 9 requirements; thus, indicating that Jordanian banks have the ability to the transition to applying the IFRS 9. 
Next comes the study of (Nimer et al., 2011) which aims to test the extent to which the application of IAS 39 affects the decisions of Jordanian inventors', both individuals and institutions, as well as to evaluate the understating of Jordanian investors of the IAS 9, along with the impact of this understanding on their investments decisions. Findings of this study reveal that the application of the IAS 39 will affect corporate profits results; therefore, reducing the Jordanian investor's contribution to these corporates. There has been no impact of the different levels of education, the certifications, and years of experience on the application of the IAS 39.

This research is distinguished of other previous studies in terms of its content as it considers the IRFS 9 as one of the new and important standards. In this research, the researcher has discussed the impact of applying the IRFS 9 on investors' decisions. As well, this study is considered one of the first studies to tackle the impact of companies' compliance with the application of this standard in terms of scope, recognition, measurement, and classification on investors' decisions in ASE; while the previous studies have discussed the replaced standard 39. In addition, there are three studies that have dealt with the IRFS 9, but they did not discuss the impact of applying this standard on the decisions of the investor who is considered one of the most important users of financial statements.

\section{Study Methodology}

The descriptive analysis approach is used and it is based on studying the case as it is in reality, accurately describing it, then analyzing and interpreting it to reach conclusions that contribute to the development of reality.

\section{Study Population and Sample}

The study population and sample consists of all investment companies, which are 33 company, listed on ASE by the end of 2015. This study relies on the opinions of brokerage managers, investment managers, and financial analysists for the companies of the study sample.

57 questionnaire have been distributed on all companies in the study sample. The number of questionnaire which are received is $54 ; 3$ of which has been disregarded due to the lack of seriousness of respondents in filling the questionnaire sections; thus, the response rate to the questionnaire has been $95 \%$.

\section{Statistical Analysis}

The Statistical Package for Social Sciences- SPSS has been used in the analysis and testing of hypothesis.

The following statistical methods have been also used:-

- Descriptive statistical tests (arithmetical mean, standard deviation, repetition).

- Cronbach's alpha test: To verify the internal consistency of the measurement tool and ensure its stability.

- Multiple regression analysis: To test the impact of the independent variables combined on the dependent variable.

- Simple regression analysis: To test the impact of independent variables on the dependent variable.

In addition to what has been mentioned above, this study has used other methods that the researcher believes important for the study objectives. 


\section{Study Model}

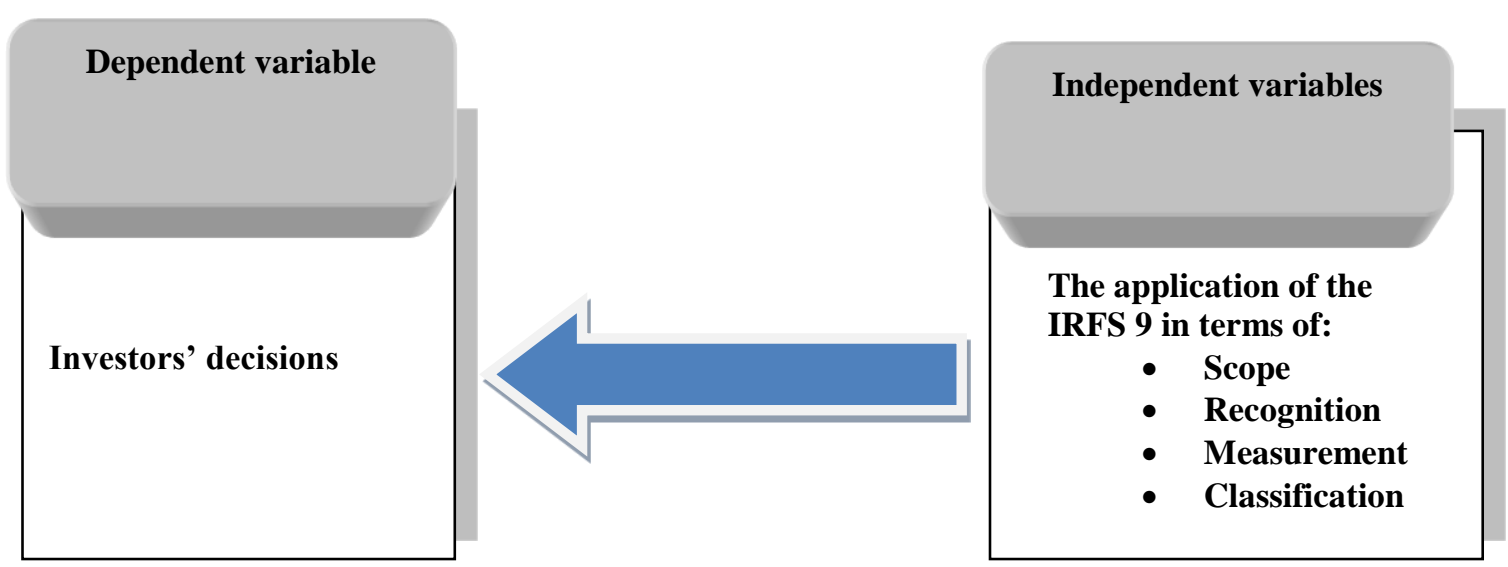

Figure 1: Research model prepared by the researchers

\section{Research Hypothesis}

In light of the research model, a group of hypotheses has been established to answer the research problem:-

Main Hypothesis: The application of the IRFS 9 in the companies listed on ASE does not affect investors' decisions.

The following sub- hypotheses are derived from the above hypothesis:

First sub- hypothesis: The compliance of companies listed on ASE with the application of the IRFS 9 scope in preparing financial statements does not affect investors' decisions.

Second sub- hypothesis: The compliance of companies listed on ASE with the recognition of financial transactions and operations in accordance with the IRFS 9 requirements does not affect investors' decisions.

Third sub- hypothesis: The compliance of companies listed on ASE with the classification of financial assets and liabilities in accordance with the IRFS 9 requirements does not affect investors' decisions.

Fourth sub- hypothesis: The compliance of companies listed on ASE with the measurement of financial transactions and operations in accordance with the IRFS 9 requirements does not affect investors' decisions.

\section{Testing of the Stability and Validity of the Study Tool}

One of the main elements that should be taken into account when preparing the questionnaire is testing it and ensuring that the stability and validity are available. The reliability factor refers to the stability of the scale and that it does not contradict itself; in other words, it should give the same results when re- applied on the same sample. To achieve this objective, the Test-Retest Reliability method is used, where the researcher has made a primary testing for the study tool on a sample consisting of 20 (brokerage managers, investment managers, and financial analysist) in investment companies listed on ASE on January 2016. The re- test is made after a while and it shows that the matching in the sample respondents is $74 \%$; thus, indicating a high degree of stability in the questionnaire. Whereas, the validity factor means that the scale measures what is set for measurement. To ensure the accuracy of the previous rate, the stability and validity of the questionnaire questions have been tested through the internal consistency equation using Cronbach's Alpha factor which determines the extent to which the measurement tool should be relied on to give the 
same results or approximate results in case the measurement operations are repeated in similar conditions on the same sample or a close one. The value of Cronbach's Alpha is as follows:

Table 1: Testing of the study tool

\begin{tabular}{|l|c|c|c|}
\hline Description & No. of Questions & Stability & Validity \\
\hline $\begin{array}{l}\text { Companies recognition of the financial transactions } \\
\text { and operations in accordance with the requirements of } \\
\text { IFRS 9 }\end{array}$ & 12 & 0.647 & 0.804 \\
\hline $\begin{array}{l}\text { Companies classification of financial assets and } \\
\text { liabilities in accordance with the requirements of the } \\
\text { IFRS 9 }\end{array}$ & 12 & 0.809 & 0.899 \\
\hline $\begin{array}{l}\text { Companies measurement of financial assets and } \\
\text { liabilities in accordance with the requirements of the } \\
\text { IFRS 9 }\end{array}$ & 7 & 0.741 & 0.922 \\
\hline Investors decisions & 7 & 0.681 & 0.825 \\
\hline Total & 47 & 0.908 & 0.953 \\
\hline
\end{tabular}

Table 1 shows that Cronbach's Alpha factor rates indicate that there is a high degree of stability in all of the questionnaire questions as Cronbach's Alpha factor has been statistically acceptable for all questionnaire components since all variables have been above $60 \%$. Overall, the questionnaire has a stability degree at 0.908. The researcher believes that the reason for this is because the fact that the members of the study sample have a long experience in the descriptive statistics as shown in table 1.

\section{The Descriptive Statistics of the Research Sample and its Variables}

Annex 1 shows that a great part of the study sample have sufficient experience and educational qualification. The rate of those who have more than five years of experience is $96 \%$ of the study sample; whereas, the rate of $\mathrm{MA}$ and $\mathrm{PhD}$ degree holders is $61 \%$ of the study sample; therefore, leading to an increase in the stability of the questionnaire as previously explained.

To show the averages of responses to the questionnaire questions, the descriptive statistical methods are used through finding the arithmetical mean and standard deviation of the responses to the questionnaire questions as well as the overall result of each area. The Likart Scale used in the search has been also properly considered. The results of these responses can be presented as follows:

Table 2: Descriptive analysis of the research questions

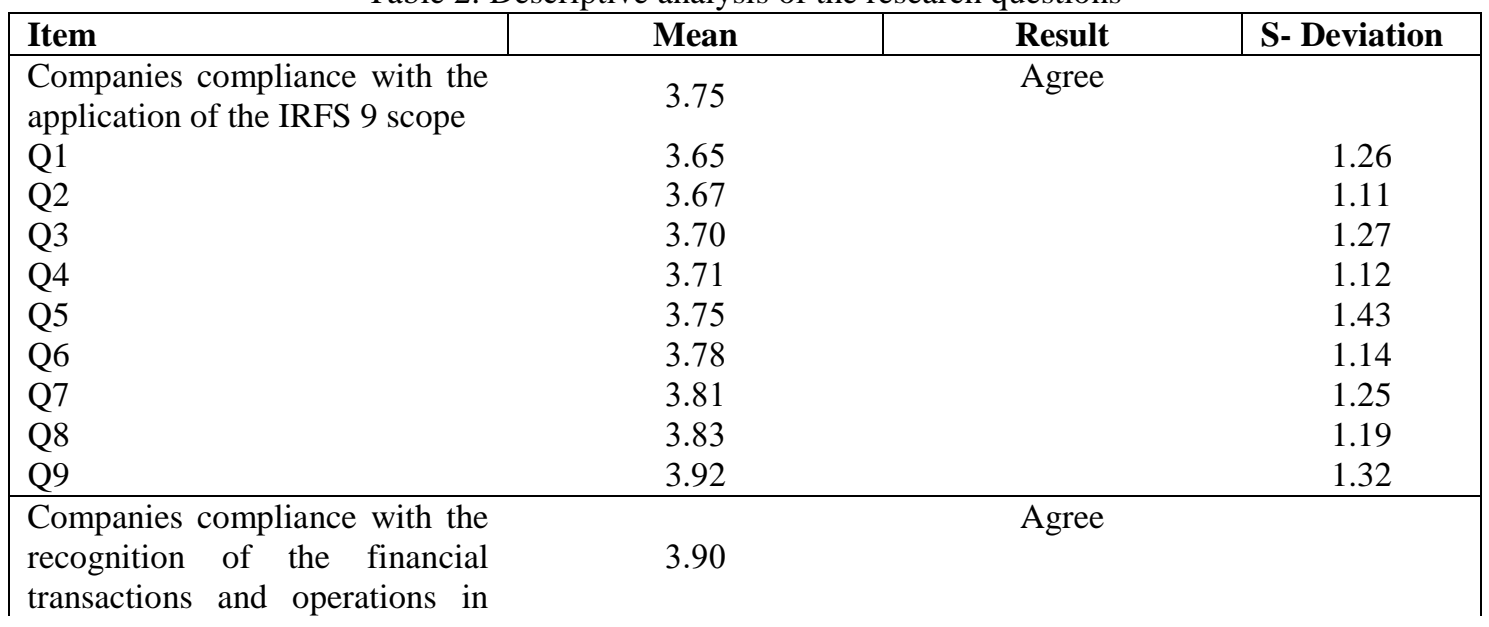




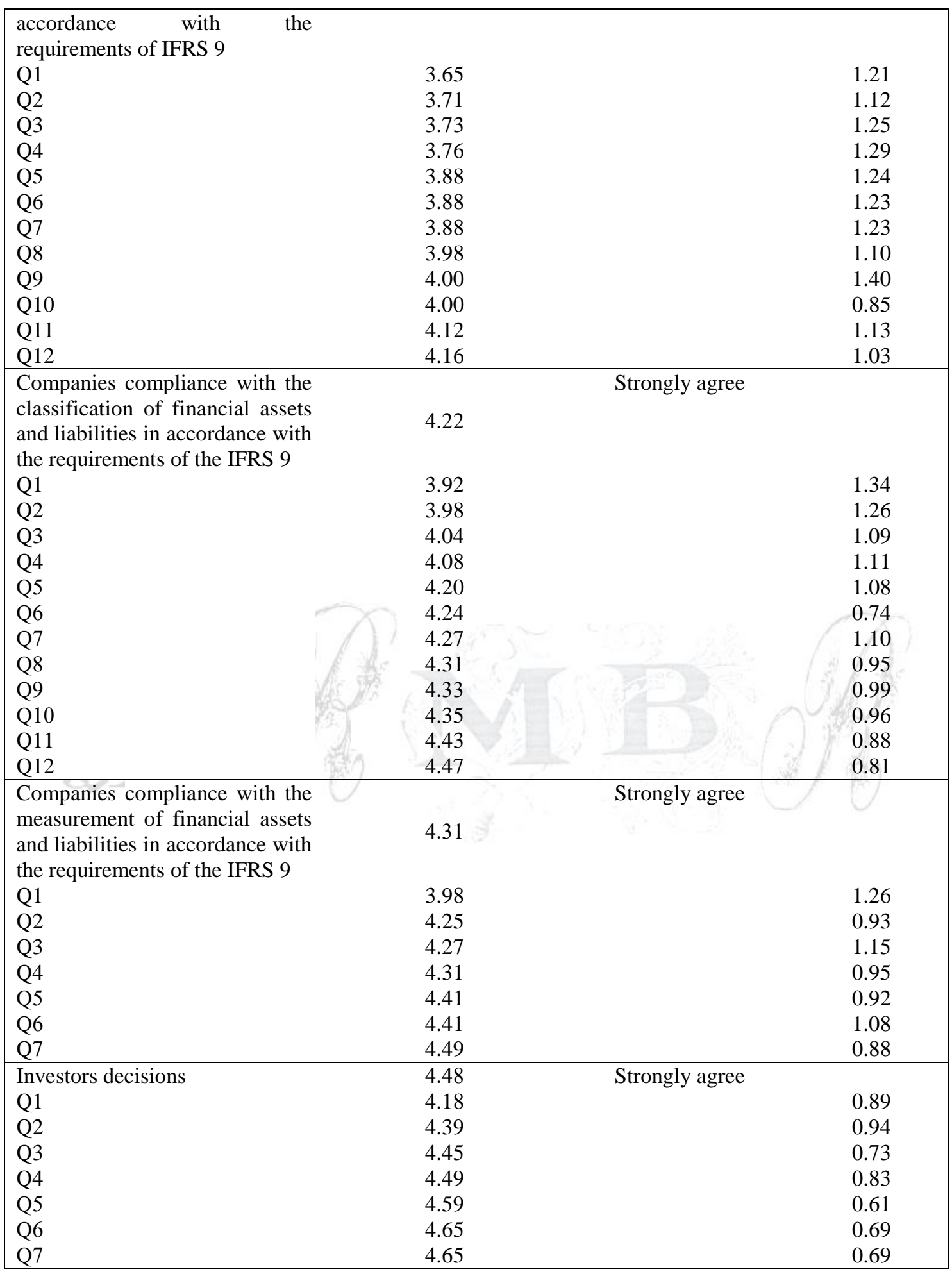

Table 2 presents the descriptive analysis of the responses to the research areas related to the independent variables and the dependent variable represented by the investors' decisions. It is revealed from the above 
table that the majority of the areas have received a strongly agree result except for the areas pertaining to the companies' compliance with the application of the IRFS 9 scope as well as companies recognition of the financial transactions and operations in accordance with the requirements of IFRS 9 which have received an agree result.

\section{Statistical Analysis Data Validation}

For the research purposes, it is important to identify the data characteristics to ensure that the relevancy of the research model through the normality distribution test. The assumptions of path analysis state that the variables' views should be normally distributed. The normality distribution test has been employed using the Kolmogorov-Smirnov test to show the normal distribution of the research variables as follows:

Table 3: The normality distribution test of the research variables

\begin{tabular}{|c|c|c|c|}
\hline \multirow[t]{2}{*}{ No. } & \multirow[t]{2}{*}{ Variable } & \multicolumn{2}{|c|}{ Kolmogorov-Smirnov } \\
\hline & & K-S & P-Value \\
\hline 1 & $\begin{array}{l}\text { Companies compliance } \\
\text { application of the IRFS } 9 \text { scope in } \\
\text { preparing financial statements }\end{array}$ & 0.098 & $0.200^{*}$ \\
\hline 2 & $\begin{array}{l}\text { Companies compliance with recognition } \\
\text { of the financial transactions and } \\
\text { operations in accordance with the } \\
\text { requirements of IFRS } 9\end{array}$ & 0.122 & 0.055 \\
\hline 3 & $\begin{array}{l}\text { Companies compliance } \\
\text { classification of financial } \\
\text { liabilities in accordance } \\
\text { requirements of the IFRS 9 }\end{array}$ & 0.209 & 0.510 \\
\hline 4 & $\begin{array}{l}\text { Companies compliance } \\
\text { measurement of financial } \\
\text { liabilities in accordance } \\
\text { requirements of the IFRS 9 }\end{array}$ & 0.142 & 0.120 \\
\hline 5 & Investors decisions & 0.183 & 0.067 \\
\hline
\end{tabular}

Moreover, the extent to which data are close to its normal distribution is also tested for all of the research continuous variables. The decision rule according to this test states that data follow the normal distribution if the probability value ( $\mathrm{P}$ - value) is greater than 0.05 . Otherwise, the normal distribution of data will be considered (Qasem et al., 2016). As indicated in table 3, all research variables follow the normal distribution. Therefore, the Parametric Tests can be used.

\section{Multicollinearity and Durbin-Watson Tests}

After testing the extent to which data are close to its normal distribution, the next step is the statistical analysis data validation test which the Multicollinearity test and Durbin-Watson Test of the study variables. Results of these test are presented as follows:-

Table 4: Multicollinearity and Autocorrelation Tests

\begin{tabular}{|l|c|c|}
\hline Variable & Multicollinearity Test \\
\hline $\begin{array}{l}\text { Companies' compliance with the application of the IRFS } \\
\text { 9 scope in preparing financial statements }\end{array}$ & 0.897 & \multirow{2}{*}{ VIF } \\
\hline $\begin{array}{l}\text { Companies' compliance with the recognition of the } \\
\text { financial transactions and operations in accordance with }\end{array}$ & 0.468 & 2.14 \\
\hline
\end{tabular}




\begin{tabular}{|l|c|c|}
\hline the requirements of IFRS 9 & & \\
\hline $\begin{array}{l}\text { Companies' compliance with the classification of } \\
\text { financial assets and liabilities in accordance with the } \\
\text { requirements of the IFRS 9 }\end{array}$ & 0.274 & 2.74 \\
\hline $\begin{array}{l}\text { Companies' compliance with the measurement of } \\
\text { financial assets and liabilities in accordance with the } \\
\text { requirements of the IFRS 9 }\end{array}$ & Durbin-Watson & 3.64 \\
\hline Autocorrelation Test & & $\mathbf{2 . 1 3 8}$ \\
\hline
\end{tabular}

After testing the Multicollinearity through the Collinearity Diagnostics scale by calculating the tolerance factor of each of the independent variables, then finding the Variance Inflationary Factor, it can be revealed from table 4 that the VIF factor for both variables did not exceed 5; indicating a multicollinearity problem in the study model.

Furthermore, the Autocorrelation Test is also used to ensure that there is no autocorrelation problem in the model through the Durbin-Watson test, where the problem appears when the adjacent values of variables are correlated; thus, affecting the validation of the model as it will indicate unreal effect due to this correlation. The values of this test ranges between (0-4). The adjacent result of (0) indicates a significantly positive correlation; whereas the adjacent result of (0) indicates a significantly negative correlation. As well, the best result ranges between $(1.5-2.5)$. This shows that there is no autocorrelation between the adjacent values of the variables. As indicated from table 12, the value of D-W calculated of the study model is 2.138 which lies within that relevant scope. Therefore, it can be found that there is no autocorrelation problem affecting the model validation.

\section{Pearson's Correlation Matrix for the Study Variables}

The researcher has relied on Pearson's correlation matrix in order to identify the correlations between all of the study variables as follows:-

Table 5: Findings of the Pearson's correlation matrix for the Study Variables

\begin{tabular}{|c|c|c|c|c|c|}
\hline Variable & $\mathrm{X} 1$ & $\mathrm{X} 2$ & X3 & $\mathrm{X} 4$ & $\mathrm{X} 5$ \\
\hline $\mathrm{X} 1$ & 1 & & & & \\
\hline $\mathrm{X} 2$ & 0.174 & 1 & & & \\
\hline X3 & 0.311* & $0.526^{* *}$ & 1 & & \\
\hline $\mathrm{X} 4$ & 0.251 & 0.640** & $0.667 * *$ & 1 & \\
\hline X5 & $0.296 *$ & $\mathbf{0 . 4 5 6 * *}$ & $\mathbf{0 . 6 3 0 * *}$ & 0.656 ** & 1 \\
\hline
\end{tabular}

Table 5 illustrates the significant correlation between the study variables in the investment companies listed on the ASE. Whereas, X1 indicates the companies' compliance with the application of the IRFS 9 scope; $\mathrm{X} 2$ indicates companies' compliance with the recognition of the financial transactions and operations in accordance with the requirements of IFRS 9; X3 indicates companies' compliance with the classification of financial assets and liabilities in accordance with the requirements of the IFRS 9; X4 shows companies' compliance with the measurement of financial assets and liabilities in accordance with the requirements of the IFRS 9; and X5 represents investors' decisions.

After examining the figures given in this table, it is found that there is a positive relationship between the independent variables of the study which are related to the application of the IFRS 9, as the highest value, 0.667 , has been between companies' classification of financial assets and liabilities in accordance with the requirements of the IFRS 9 and companies' compliance with the measurement of financial assets and liabilities in accordance with the requirements of the IFRS 9. As well, it is also observed that there is appositive relationships between all independent variables of the study and the independent variables 
(investors' decisions), as the highest correlation, which is 0.656 , has been between companies' compliance with the measurement of financial assets and liabilities in accordance with the requirements of the IFRS 9 and the investors' decision.

\section{Study Hypotheses Testing}

\section{Main Hypothesis: The application of the IRFS 9 in the companies listed on ASE does not affect investors' decisions.}

In order to prove or disprove the first hypothesis, the researcher has used the multiple regression analysis method, where he relied on Fisher distribution (f) to judge the explanatory power of the model as a whole as well as the extent to which the proposed model is relevant to the representation of the correlation between the independent variables and the dependent variable. F- Calculated should be greater than its Tabulated value at a confidence level of (0.95) in order to accept the model. In addition, T-Calculated is also used to identify the impact of the independent variables on the dependent variable. The absolute value of t- calculated should be greater than its tabulated value at a significance level less than 0.05 in order to reject the null sub- hypothesis and accept the alternative hypothesis. As well, Adjusted R Square will be also employed for indicating the extent to which the interpretation of the independent variable to the dependent variable is accurate.

Table 6: Multiple regression analysis test results for the impact of applying the IRFS 9 on investors' decisions.

\begin{tabular}{|c|c|c|c|c|c|}
\hline \multirow{2}{*}{$\begin{array}{c}\text { Sig } \\
0.000\end{array}$} & \multirow{2}{*}{$\begin{array}{c}\text { F test Model } \\
12.690\end{array}$} & $\mathbf{R}$ & R Square & Adjusted R Square & \multirow{2}{*}{ 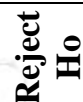 } \\
\hline & & 0.669 & 0.448 & 0.403 & \\
\hline
\end{tabular}

Table 6 shows the results of the multiple regression analysis for the independent variables (companies' compliance with the application of the IRFS 9 scope, companies' compliance with the recognition of the financial transactions and operations in accordance with the requirements of IFRS 9, companies' compliance with the classification of financial assets and liabilities in accordance with the requirements of the IFRS 9, and companies' compliance with the measurement of financial assets and liabilities in accordance with the requirements of the IFRS 9) and their impact on the dependent variable (investors' decisions). F- Calculated has been (12.690), which is greater than its tabulated value at a confidence level of (0.95), which equals (4.05). Therefore, this indicates that this model is relevant and has a high explanatory power. As well, this result emphasizes that (sig f) is less than (0.05), as it was (0.000). Thus, the main null hypothesis is rejected and the alternative hypothesis is accepted. This indicates that there is an impact for the application of the IRFS 9 represented by each of (companies' compliance with the application of the IRFS 9 scope in the preparation of financial statements, companies' compliance with the recognition of the financial transactions and operations in accordance with the requirements of IFRS 9, companies' compliance with the classification of financial assets and liabilities in accordance with the requirements of the IFRS 9, and companies' compliance with the measurement of financial assets and liabilities in accordance with the requirements of the IFRS 9) on investors' decisions in the Jordanian investment companies listed on ASE. The researcher believes that the reason for this goes to the fact that the IFRS 9 contains detailed application instructions based on clear foundations that are not left to personal judgment; therefore, contributing to the improvement of the quality of accounting information and improving the quality of the investment decision.

It is worth mentioning that this study complements other previous studies, which are: (Al Hayek \& El Haija, 2011, Takrouri, 2015, and Al- Khatib, 2015) which have tackled different aspects of the IFRS 9 and have been applied to the financial sector on ASE (banks). To begin with, the study of (Al Hayek \& El Haija, 2011), conducted when the IFRS 9 was issued, has examined the extent to which accountants in 
Jordanian banks have knowledge of the IFRS 9 requirements. This study finds that Jordanian banks have the ability to the transition to the application of the IFRS 9.

The following is the study of (Takrouri, 2014) which complements what the previous study has reached and it investigates how Jordanian commercial banks face difficulties when applying the IFRS 9. This study concludes that Jordanian banks do not face difficulties in the application of the IFRS 9. Next comes the study of (Al- Khatib, 2015) which also complements the two previous studies as it identifies the impact of applying the IFRS 9, in terms of measurement, on the accounting information quality. This study reveals that there is an impact for applying the IFRS 9, in terms of measurement, on the improvement of the accounting information quality. As well, this study also complements other studies as it examines the impact of applying the IFRS 9 on investment decisions in the investment companies listed on ASE in the financial sector. The study also finds that there is an impact for compliance with the application of the IFRS 9 in terms of (scope, recognition, classification, and measurement) on the quality of the investment decisions. This result agrees with the studies of (Qassas, 2002), (Al Hyesat, 2013), and (Nimer et al., 2011) which indicate that there is an impact for the IAS 39 on the investment decisions.

Moreover, it is also noticed that the Adjusted R Square is (0.403) which indicates the accuracy of interpretation by the dependent variable (investors' decisions) through the independent variables represented by each of (the compliance with the application of the standard in the preparation of financial statements, the compliance with the recognition of the financial transactions and operations in accordance with the standard requirements, the compliance with the classification of financial assets and liabilities in accordance with the standard requirements, and the compliance with the measurement of financial assets and liabilities in accordance with the standard requirements) combined.

To discuss the sub- hypotheses, the researchers has relied on the multiple regression analysis outputs as in the following table:

Table 7: Multiple regression analysis test results for the study variables.

\begin{tabular}{|c|c|c|c|c|}
\hline Model & B & Coefficients & T & Sig \\
\hline Constant & 2.186 & --- & 5.208 & 0.000 \\
\hline X1 & 0.217 & 0.104 & 2.401 & 0.045 \\
\hline X2 & 0.294 & 0.120 & 3.142 & 0.031 \\
\hline X3 & 0.312 & 0.232 & 3.981 & 0.013 \\
\hline X4 & 0.437 & 0.439 & 5.142 & 0.001 \\
\hline
\end{tabular}

X1 refers to companies' compliance with the application of the standard scope; X2 refers to companies' recognition of the recognition of the financial transactions and operations in accordance with the standard requirements; X3 indicates companies' classification of financial assets and liabilities in accordance with the standard requirements; X4 refers to companies' compliance with the measurement of financial assets and liabilities in accordance with the standard requirements; and X5 indicates investors' decisions.

First sub- hypothesis: The compliance of companies listed on ASE with the application of the IRFS 9 scope in preparing financial statements does not affect investors' decisions.

Results show that the value of the correlation coefficient is (0.104) which indicates that there is a statistically significant positive correlation between the dependent variable and independent one, meaning that the greater the compliance of companies listed on ASE with the application of the IRFS 9, the better the quality of investors' decisions will be. Furthermore, the study findings point out that the absolute value of T-Calculated is 2.401) which is greater than its tabulated value of (1.677) at a confidence level of (0.95). This finding emphasizes the (Sig T) has been less than (0.05) as it was (0.045). According to the Decision Rule which assumes the rejection of the null hypothesis (Ho) if T-Calculated is greater than its tabulated value when Sig $\mathrm{T}$ is less than (0.05). Therefore, the application of the IRFS 9 scope affects investors' 
decisions. Hence, the first null sub- hypothesis is rejected and the alternative hypothesis is accepted. In other words, the compliance of companies listed on ASE with the application of the IRFS 9 scope in preparing financial statements affects investors' decisions. The researcher believes that this is due to the fact that the IRFS 9 has added an option to include some contracts that have reduced the level of personal judgement and led to the reliance on more objective and scheduled scientific methods. As well, standard 9 has added clear scientific foundations to standard 39 for applying it on some loan commitments and liabilities relating to impairment requirements, which did not exist in the items of standard 39. It is worth mentioning that this hypothesis has not been measured in any of the previous Arab or foreign studies.

Second sub- hypothesis: The compliance of companies listed on ASE with the recognition of financial transactions and operations in accordance with the IRFS 9 requirements does not affect investors' decisions.

The compliance of companies listed on ASE with the application of the IRFS 9 scope in preparing financial statements does not affect investors' decisions.

Results show that the value of the correlation coefficient is $(0.120)$ which indicates that there is a statistically significant positive correlation between the dependent variable and independent one, meaning that the greater the compliance of companies listed on ASE with the recognition of the IRFS 9 requirements, the better the quality of investors' decisions will be. Furthermore, the study findings point out that the absolute value of T-Calculated is (3.142) which is greater than its tabulated value of (1.677) at a confidence level of (0.95). This finding emphasizes the (Sig T) has been less than (0.05) as it was (0.031). According to the Decision Rule which assumes the rejection of the null hypothesis (Ho) if T-Calculated is greater than its tabulated value when Sig T is less than (0.05). Therefore, the recognition of the IRFS 9 requirements affects investors' decisions. Hence, the second null sub- hypothesis is rejected and the alternative hypothesis is accepted. In other words, the compliance of companies listed on ASE with the recognition of financial transactions and operations in accordance with the IRFS 9 requirements in preparing financial statements affects investors' decisions. The researcher believes that this is due to the fact that standard 9 has transferred the framework relating to the initial recognition from standard 39 and it has added an item pertaining to the recognition of profits and losses in the sale and purchase; therefore, enhancing the quality of information and improving the quality of investors' decisions. It is worth mentioning that this hypothesis has not been measured in any of the previous Arab or foreign studies.

Third sub- hypothesis: The compliance of companies listed on ASE with the classification of financial assets and liabilities in accordance with the IRFS 9 requirements does not affect investors' decisions.

Results show that the value of the correlation coefficient is $(0.232)$ which indicates that there is a statistically significant positive correlation between the dependent variable and independent one, meaning that the greater the compliance of companies listed on ASE with the classification of financial assets and liabilities in accordance with the IRFS 9 requirements, the better the quality of investors' decisions will be. Furthermore, the study findings point out that the absolute value of T-Calculated is (3.142) which is greater than its tabulated value of (1.677) at a confidence level of (0.95). This finding emphasizes the (Sig T) has been less than (0.05) as it was (0.031). According to the Decision Rule which assumes the rejection of the null hypothesis (Ho) if T-Calculated is greater than its tabulated value when Sig T is less than (0.05). Therefore, the recognition of the IRFS 9 requirements affects investors' decisions. Hence, the third null sub- hypothesis is rejected and the alternative hypothesis is accepted. In other words, the compliance of companies listed on ASE with the classification of financial assets and liabilities in accordance with the IRFS 9 requirements in preparing financial statements affects investors' decisions. The researcher believes that the reason for this goes to the fact that standard 9 has reduced the categories set for classification into three categories represented by each of (amortized cost, fair value through the profit or loss, and fair value by the other comprehensive income) with reliance on the institution business, in addition to setting sufficient and clear instructions for the application of the classification requirements and issuing necessary 
instructions for the implementation, illustrative examples, and practical cases that have facilitated the application process. Thus, this has led to the improvement of financial statements quality; which in turn has improved the quality of investors' decisions. It is worth mentioning that this hypothesis has not been measured in any of the previous Arab or foreign studies.

Fourth sub- hypothesis: The compliance of companies listed on ASE with the measurement of financial transactions and operations in accordance with the IRFS 9 requirements does not affect investors' decisions.

Results show that the value of the correlation coefficient is $(0.439)$ which indicates that there is a statistically significant positive correlation between the dependent variable and independent one, meaning that the greater the compliance of companies listed on ASE with the measurement of financial transactions and operations in accordance with the IRFS 9 requirements, the better the quality of investors' decisions will be. Furthermore, the study findings point out that the absolute value of T-Calculated is (5.142) which is greater than its tabulated value of (1.677) at a confidence level of (0.95). This finding emphasizes the (Sig T) has been less than (0.05) as it was (0.001). According to the Decision Rule which assumes the rejection of the null hypothesis (Ho) if T- Calculated is greater than its tabulated value when Sig T is less than (0.05). Therefore, the measurement in accordance with the IRFS 9 requirements affects investors' decisions. Hence, the fourth null sub- hypothesis is rejected and the alternative hypothesis is accepted. In other words, the compliance of companies listed on ASE with the measurement of financial transactions and operations in accordance with the IRFS 9 requirements in preparing financial statements affects investors' decisions. The researcher believes that standard 9 has removed the uncertainty state which was in standard 39 by adding necessary amendments to the subsequent measurement of financial assets, particular, those financial assets which are subsequently measured by the amortized cost that was not included in standard 39. As well, standard 9 has added highly significant amendments relating to the impairment requirements by developing a dual measurement method through which the loss value is measured; therefore, avoiding personal judgment in measuring the loss value as previously followed in standard 39. It is worth mentioning that this hypothesis has not been measured in any of the previous Arab or foreign studies.

After discussing the sub- hypotheses and by referring to table 7, the linear regression equation of the independent variables combined is set as follows:-

$\mathrm{Y}=2.186+(0.217 * \mathrm{X} 1)+(0.294 * \mathrm{X} 2)+(0.312 * \mathrm{X} 3)+(0.437 * \mathrm{X} 4)+\mathrm{e}$

Where:-

Y: refers to investors' decisions.

$\mathrm{X} 1$ : refers to companies' compliance with the application of the standard scope.

$\mathrm{X} 2$ : refers to companies' compliance with the recognition of financial transactions and operations in accordance with the standard requirements.

X3: refers to companies' compliance with the classification of financial assets and liabilities in accordance with the standard requirements.

X4: refers to companies' compliance with the measurement of financial assets and liabilities.

e: refers to errors rate.

\section{Results}

The study results can be summarized as follows:

1. There is an impact of the compliance of companies listed on ASE with the application of the IRFS 9 scope in preparing financial statements on investors' decisions. The researcher believes this is due to 
the fact that the IRFS 9 has added an option to include some contracts which have reduced the level of personal judgement and led to the reliance on more objective and scheduled scientific methods. As well, standard 9 has added clear scientific foundations to standard 39 to be applied on some loan commitments and liabilities relating to the impairment requirements, which did not exist in the items of standard 39.

2. There is an impact of the compliance of companies listed on ASE with the recognition of financial transactions and operations in accordance with the IRFS 9 requirements on investors' decisions. The researcher believes this is due to the fact that standard 9 has transferred the framework relating to the initial recognition from standard 39 and it has added an item pertaining to the recognition of profits and losses in the sale and purchase; therefore, enhancing the quality of information and improving the quality of investors' decisions.

3. There is an impact of the compliance of companies listed on ASE with the classification of financial assets and liabilities in accordance with the IRFS 9 requirements on investors' decisions. The researcher believes the reason for this goes to the fact that standard 9 has reduced the categories set for classification into three categories represented by each of (amortized cost, fair value through the profit or loss, and fair value by the other comprehensive income) with reliance on the establishment business, in addition to setting sufficient and clear instructions for the application of the classification requirements and issuing necessary instructions for the implementation, illustrative examples, and practical cases that have facilitated the application process. Thus, this has led to the improvement of financial statements quality; which in turn has improved the quality of investors' decisions

4. There is an impact of the compliance of companies listed on ASE with the measurement of financial transactions and operations in accordance with the IRFS 9 requirements on investors' decisions. The researcher believes this is because that standard 9 has removed the uncertainty state which was in standard 39 by adding necessary amendments to the subsequent measurement of financial assets, particularly, those financial assets which are subsequently measured by the amortized cost that was not included in standard 39. As well, standard 9 has added highly significant amendments relating to the impairment requirements by developing a dual measurement method, through which the loss value is measured; therefore, avoiding personal judgment in measuring the loss value as previously done in standard 39.

5. There is an impact of applying the IRFS 9 in the companies listed on ASE on investors' decisions. The researcher believes the reason for this goes to the fact that the IFRS 9 includes detailed application instructions based on clear foundations which are not left to personal judgment. This has contributed to the improvement of the accounting information quality, and therefore, improving the investment decision quality as well.

\section{9- Recommendations:}

Based on the study findings, the following recommendations are made:-

1. Following up and monitoring the activities of such companies by legislative parties as well as regulatory and supervisory institutions in terms of financial operations, preparation of systematic calculations, and the implementation mechanism of international standards, in general, and the IRFS 9, in particular.

2. Urging investors to gain deeper understanding of the realities of Jordanian companies in order to identify their infrastructure and accounting system to determine the extent to which they agree with the international accounting standards; thereby, encouraging them for investment.

3. Raising awareness amongst financial managers and accountants in all sectors regarding the importance of early application of IFRS 9 due to its direct impact on the financial results of companies. This should be done before the mandatory application date in 2018, so as these parties will benefit from being exempted from the requirement of re- presentation of financial statements for the previous periods in case the application has been prior to the mandatory date.

4. Conducting a similar study on other economic sectors within the Jordanian environment for comparison purposes to identify the similarities and differences between these sectors in applying the IFRS 9 on investment decisions. 
5. Conducting comparative studies on attracting direct foreign investment before and after the application period of the IFRS 9 by Jordanian companies.

\section{References}

Abu Nassar, Mohammed and Hmeidat, Juma' (2014), IFRSs: Scientific and Theoretical Aspects, Edition.3, Dar Wael for Publishing and Distribution.

Al Hyesat, Eyad (2013): The Impact of Disclosure of Finance Statements on Investors' Decisions in Jordanian Service Companies Listed on ASE, (Un published MA thesis), Yarmouk University, Irbid, Jordan.

Al- Khatib, Firas (2015): The Impact of Applying the IFRS 9 on the Improvement of the Accounting Information Quality: An Applied Study on Jordanian Commercial Banks, (Un published MA thesis), Applied Science Private University, Amman, Jordan.

Al Najjar, Khalil (2013): The Impact of Applying the Fair Value Accounting on the Reliability and Relevancy of Financial Statements of the Palestinian Public Corporations: An applied study from the viewpoint of auditors and financial managers, Jordan Journal of Business Administration, Vol 9, No. 3, P. 465-492.

Alhayek, A.F. and Elhaija , F.A. (2011),"The Adoption of IFRS(9) in the Jordanian Banking Sector are Accountant ready to Adopt by understanding the Recognition and measurement", International Journal of Economics \& Financial Studies, Vol 1 Issue 1 Dec (2011).

Alkhadash, H. and Abdullatif, M. (2009), Consequences of Fair Value Accounting for Financial Instruments in Developing Countries: The Case of the Banking Sector in Jordan, Jordan Journal of Business Administartion, Volume 5, No. 4, 2009.

Arnouq, Baha' (2012): The Impact of Transition to the Application of the IFRS 9 in the Measurement of Financial Instruments for the Banks Listed on Damascus Securities Exchange: An applied study, Damascus University Journal of economic and legal Sciences, Vol 30, No. 1 2014, p. 561-584.

Dakhl Allah, Dina (2005): The Impact of Applying the IFRS 9 on the Stock Returns: An Analytical Study on the Financial Statements of Jordanian Commercial Banks, (Un published MA thesis), Al al- Bayt University, Al-Mafraq, Jordan.

International Financial Reporting Standards Foundation: (2015), (IFRSs), version of 1/1/2015, International Arab Society of Certified Accountants IASCA, Amman, Jordan.

Matar, Mohammed (2015), Investment Management: Theoretical Framework and Scientific Applications, Edition. 7, Amman, Dar Wael for Publishing and Distribution.

Nimer, M., Idris, M., Okdeh, S., \& Nassar, M. (2011) "The Effect of the Implementation of the IAS 39 on the Jordanian Investors", International Business Research, Vol. 4, No. 4; October 2011.

Qassas, Khalil (2002): the Impact of Disclosure of Financial Statements of Jordanian Commercial Banks on Investors' Decisions in ASE in light of the IAS 9: A comparative study, (An Un published MA thesis), Amman Arab University for Graduate Studies, Amman, Jordan.

Takrouri, Hasan (2015), Difficulties Facing Jordanian Commercial Banks in the Early Application of the IFRS 9: An applied study, (Un published MA thesis), Applied Science Private University, Amman, Jordan.

www.kpmg.com 


\section{Appendix}

Annex 1: Demographic Distribution of the Research Sample

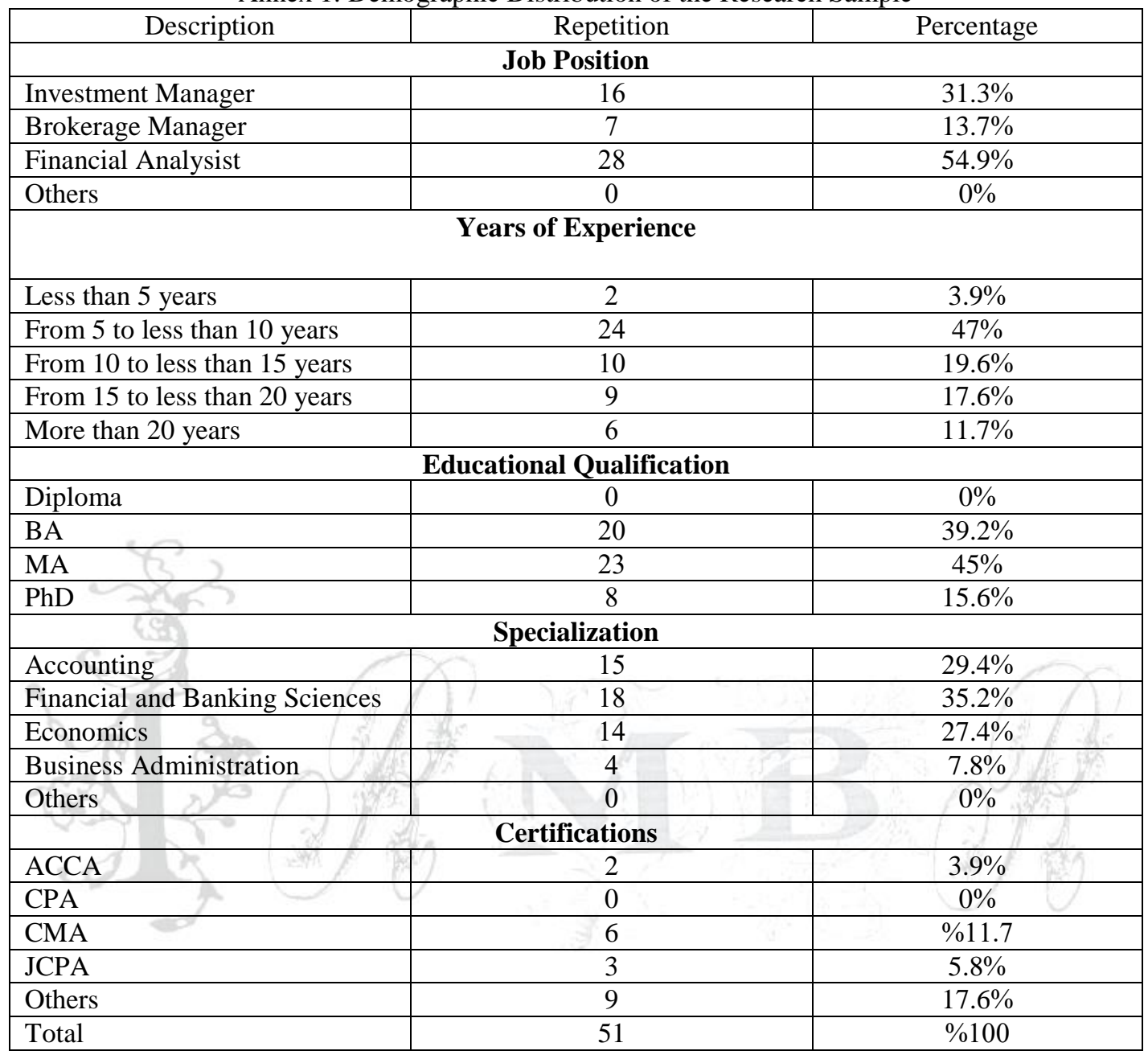

